\title{
Form Bionic Design of the High-Rise Buildings
}

\author{
Lan Ma \\ Institute of Art \& Fashion Tianjin Polytechnic University, Tianjin, China \\ 345370948@qq.com
}

\begin{abstract}
The Paper put forward the current problem that form bionic design only stressed the form and sought for the bionic design regardless of the practical results by introducing high-rise buildings and form bionic design. Taking traditional Chinese cornice design and Belgian designer Vincent Callebaut's "butterfly” design as examples, the author expounded the principle of form bionic design and pointed out such a design must go through the cultural transformation before it can really reflect the ideological values and cultural standards of humans.
\end{abstract} design

Keywords-high-rise buildings; bionic design; form bionic

At the end of the film "Rise of the Planet of the Apes", the scene that apes rush out of San Francisco built with reinforced concrete and run into the vast forest collectively shows the director's desire to return to nature. With the constantly expanding cities where humans live today, a majority of them keep away from our familiar nature. "As a species, humans are originally a part of nature. Once they get away from nature, they will feel greatly frustrated like fish which leave the sea and live in a fishbowl, so it seems that lots of things are missing in their life. [1]" However, those artifacts with natural features can often remind people of good memories of nature and arouse their emotional resonances. At the same time, modern people are also rather willing to accept such a method of getting close to nature, which's perhaps the most original demand for form bionic design.

Bionic design is actually a return to nature. Humans can't be omniscient, so it's an important way for us to understand nature by learning from the nature with a history of billions of years. Form bionic design is an important manifestation of the bionic design. The process of the design experiences by virtue of such a method is just the specific interpretation of "natural harmony" and "natural law". The Paper will explore the significance of form bionics with high-rise buildings as objects.

\section{IMPORTANCE OF High-Rise BUILDINGS IN URBAN DESIGN}

In the historical process of constructing buildings and towers in all ages, humans always show the "lofty" nature of "conquering" the universe and also deliver their tastes, ideals and spirits in different ages. In terms of high-rise buildings, contributing to cities is an inevitable choice of the development of human society. They solve the demands for the increasing habitable and living areas with the population growth and expand the urban scale. Whether active or not, high-rise buildings are influential core factors in cities in all cases.

After the urban production and consumption levels develop to a certain extent, urban designers always plan to increase the height of high-rise buildings. Besides, practice has proved that they can bring obvious social and economic benefits. First, they solve the increasing population problem. High-rise buildings centralize the population and shorten the communication distance between humans with the scientifically-designed horizontal and longitudinal paths within the buildings, thus enhancing the communication efficiency between humans; second, the per unit area of land is extensively expanded in terms of its usable space, solving the land use problem in central parts of cities; third, the investment of the municipal construction is reduced and the construction period is shortened. Most importantly, the most magnificent high-rise building in a city or area often becomes the landmark building and manifests the cultural environment locally now.

However, people have had to re-examine those energy-intensive high-rise buildings built with reinforced concrete because of the severe ecological and environmental problems since the 20th century. Today's architects must get rid of shackles of the school and commercial speculation and return to the environmental and ecological design origins to redefine the creative direction of the design of high-rise buildings. High-rise buildings boasting of high efficiency, low consumption and ecological balance have become an inevitable development trend. The ecological design of high-rise buildings consists of diverse design methods, of which, the one based on bionics can create the vivid form of "relatives" and the harmonious and comfortable ecological environment. The originality of ecological high-rise buildings from the bionic strategy will connect humans and nature organically.

\section{FORM BIONIC DESIGN}

Here we can't help asking what bionics and bionic design are. Regretfully, there hasn't been a clear answer at present. Dr. Jack Ellwood Steel first put forward the concept of bionics at the first seminar on bionics held in America and defined, "Bionics is a science of building the 
technological system by imitating the principle of the biological system or making the artificial technologies similar to the biological principle." Bionics is derived from Latin "Bion", meaning "the way of life". The suffix "ic" means "with the features of..." Therefore, we may also define bionic design accordingly, "It's an imitative design of all existing substances in nature, including organic ones (such as animals, plants, humans and microorganisms) and inorganic ones (such as the sun, the moon, mountains, rocks, wind, rain, thunder and lightning)."

As an independent science, bionics which was born in the 1960s provides humans with more flexible, reliable, efficient and economical technological systems through studies and researches of the natural world. Bionic design science, also called design bionics, is an emerging interdisciplinary subject on the basis of bionics and design science. It's mainly related to mathematics, biology, electronics, physics, cybernetics, information theory, ergonomics, psychology, material science, mechanics, dynamics, engineering, economics, chromatics, aesthetics, communication theory, ethics and other relevant sciences. The research contents of bionic design science is hard to be classified as it has a rather wide range of researches with rich contents, and especially, bionics and design science are related to lots of sciences in natural science and social science[2]. In the architectural design field, external form bionics, usable function bionics, organization structure bionics, material bionics and environment bionics are widely used.

The application methods of bionic architecture design can be concluded in four aspects roughly, namely, urban environment bionics, usable function bionics, form bionics and organization structure bionics, of which, form bionics has been the most widely used way so far. The Paper exactly studied the application of methods of form bionic design. Due to limitations on space, the Paper illustrated by means of figures as much as possible.

There are two main principles of form design, namely, imitation objects and imitation methods.

Classification description of imitation objects. (Table 1)

TABLE 1 DESCRIPTION OF IMITATION OBJECTS

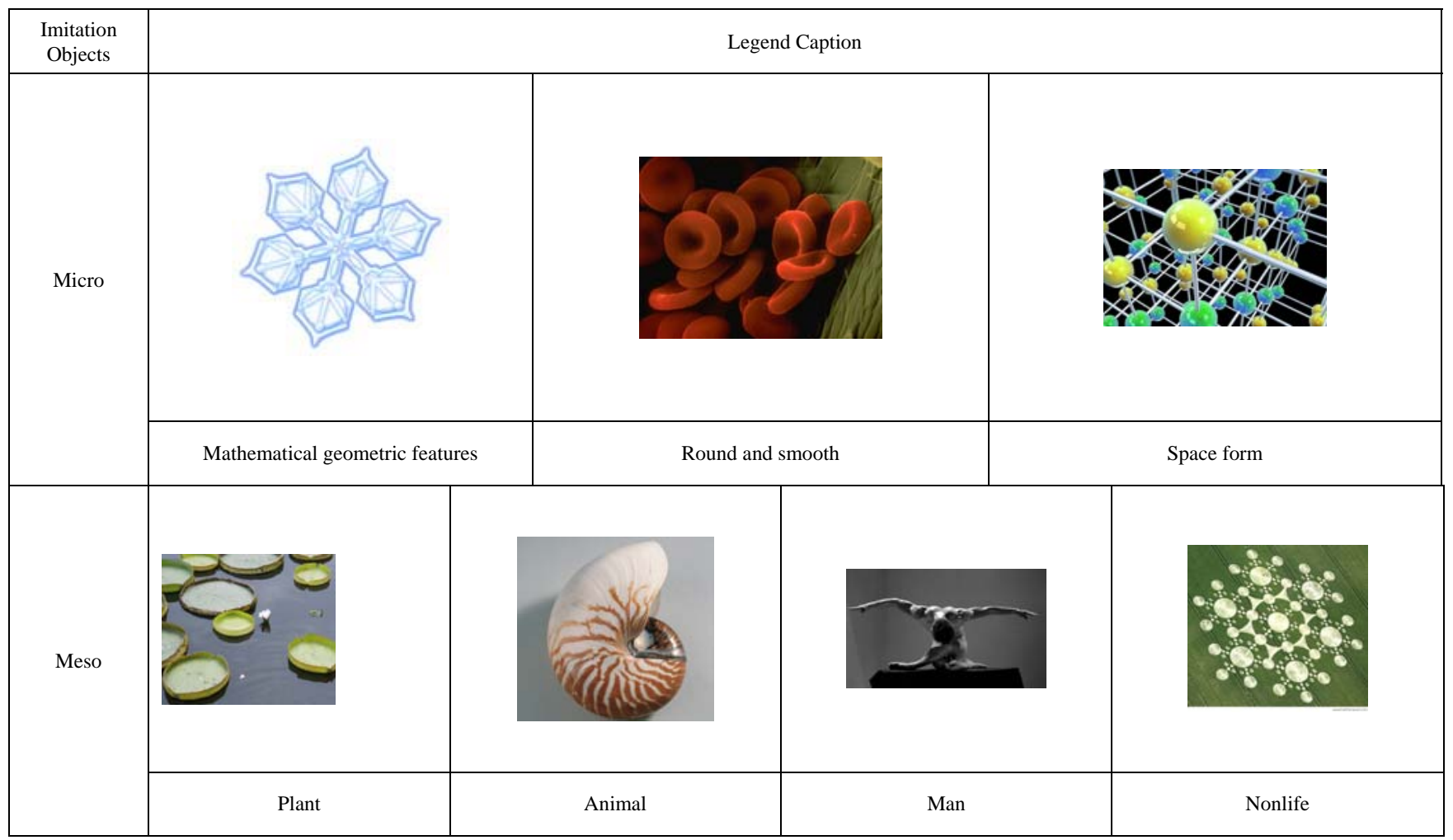




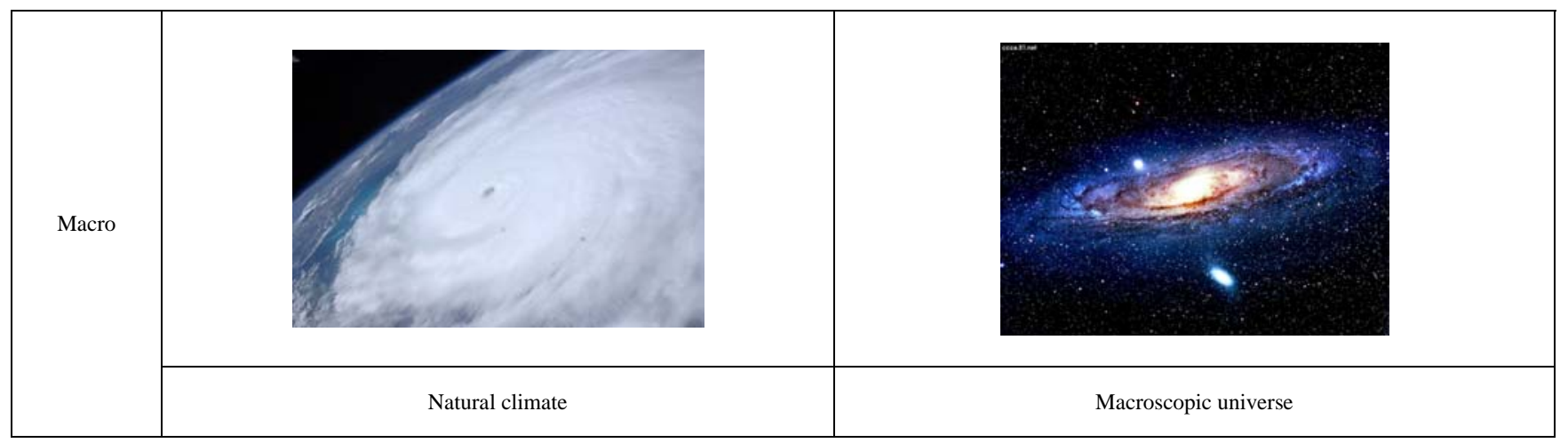

Classification of imitation methods is as follows:

Figurative imitation

Figurative imitation always follows "principles of simplicity and regularity." That is, design vague and irregular images and things into simple and regular ones after a series of processes.

Abstract Imitation

Currently, in terms of design, when we create specific design, we always apply abstract design according to the object's features as the completely figurative design is unrelated to the main imitation object that contains complex structure.

\section{FORM BIONICS IS APPLIED TO THE DESIGN OF HIGH-RISE BUILDINGS}

With the popularity of high-rise buildings, their design methods and construction technologies are being improved. Since the 21st century, more significant requirements for "being in harmony with the environment", "environmental friendly" and "energy-saving" have become the leading subject of the design of high-rise buildings. Form bionic method, an important bionic design method naturally attracts the attention of high-rise building designers. Therefore, high-rise buildings which are different from the traditional short buildings appear in cities. With various shapes, they are like towers or bridges, adding diversified elements to cities.

\section{PRoblems THAT Form Bionic ARCHITECTURE DESIGN FACES}

The laws of certain creatures' functional organizations and image construction are studied in bionic architecture to explore the rational and scientific construction laws in nature. Such research results can enrich and improve the building design methods to perfect the efficient design and reasonable shape of building structures, functions and layouts. Therefore, more and more bionic design techniques are applied to the design of high-rise buildings. At the same time, as people's taste improves with the increase of the material level, the design of high-rise buildings tends to meet the requirements for culture aspects. What is more, when a high-rise building design project invites bids, different humanistic design programs proposed by different design organizations become key factors to impress decision-makers. Hence, the design style in accordance with "natural law" brings bionic design to the forefront of high-rise buildings, which is the most urgent and widest need of design currently. How to add human factors and technology factors to bionic design process scientifically is the essence and key to the design of high-rise buildings.

With the popularity of eco-design, bionic design methods are applied to plenty of building design in a one-sided and distorted way, resulting in a vicious cycle that eco-design and bionic design are created intentionally. The successful bionic design of the Sydney Opera House leads to the fact that the shape of sea shells is applied to all kinds of related or unrelated buildings in numerous coastal cities.

Originality has no limitation, so designers certainly can collect referential elements from everything. However, the resemblance in appearance is just the basic presentation of design concept. Bionic design collects referential elements from creatures that evolved naturally. For instance, birds we see today have experienced the most scientific evolution according to the law of nature. However, the direct application of a bird's shape in humans' construction activities may not be right. Bird's biological elements shouldn't be directly adopted without combining with humans' cultural standards and concepts. Ancient Chinese had long grasped the essence of bionic architecture design. For example, they designed cornice (Fig. 1 and Fig. 2) which is one of the entablature forms of Chinese traditional architecture. The rear of its roof tilts upward, looking like a light and perky swallow which is about to fly with outspread wings, so it's also called cornice with rake angles frequently. Such a design can not only enlarge the lighting surface, but also help drain off the rainwater. Moreover, it also makes the building looks dynamically vigorous as if its roof is lifted by the air. The layers of cornices on a group of buildings make the buildings look even more spectacular with exclusively dynamic and perky characteristics of Chinese ancient architecture. 


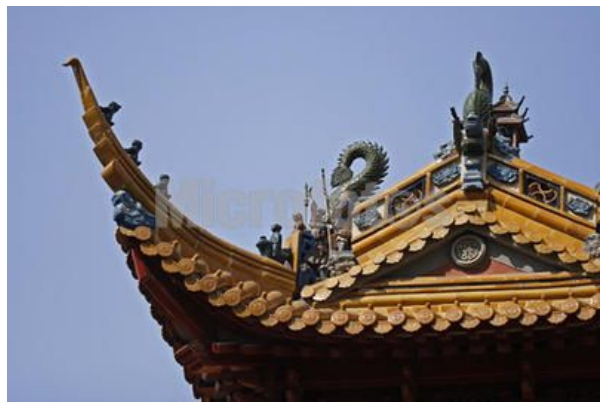

Figure 1

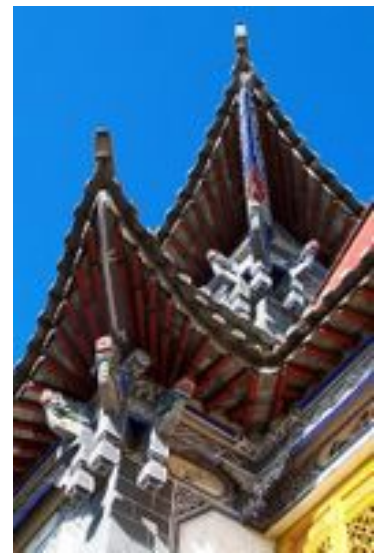

Figure 2

The ancients designed based on cultural standards. Instead of simply imitating the appearance of natural creatures, they applied the symbolic meaning to constructions. Nowadays, some designers only focus on superficial form without cultural-standard transformation in their design. Accordingly, they design a batch of strange and weird buildings just to suit their purpose of bionic design. Therefore, bionic design adopts natural elements, but they must be enriched with cultural elements so as to reflect the ideological values and cultural standards of humans.

\section{V.APPLICATION OF FORM BIONICS IN THE DESIGN OF HigH-RISE BUILDINGS}

Form bionic design makes buildings come alive harmoniously. However, the human theme is particularly important in the design. It's profoundly reasonable that creatures' forms can be preserved from the natural selection. Form bionics comes from nature which provides various creative elements for designers. The vivid and vibrant forms of buildings also bring the nature closer to users and observers. A 600-meter-tall eco-bionic building which looks like a flying butterfly externally may be built up on Roosevelt Island, New York (Fig. 12). Its designer Vincent Callebaut from Belgian plans to make its giant wings into a vertical greenhouse in which people can grow as many as 28 kinds of crops, raise livestock and even live and work. These two wings of "iron glass" are connected with the two main towers of this high-rise building and a large greenhouse is built around the main towers. In winter, the green house can keep warm by virtue of solar energy, while in summer, it can also keep cool via plant's metabolism and natural ventilation.

Its use of water resources is also quite energy-saving. The numerous rainwater absorbed by the outdoor vertical garden in the rainy season and the indoor liquid waste will be turned into agricultural water after purification.

This 132-storey "butterfly" brings us a new way of life. Seen from afar, when the first ray of morning sunshine penetrates the wings of the huge "butterfly" and everything inside becomes thriving, it seems to shake its green wings to bring boundless vitality to the city. Inside or outside the building, you will always be touched by its nimble rhythm and immerge in its atmosphere heart and soul.

This design is a very good solution to the limitations of the bionic design rather than simple imitation of the shape. Combined with the ecological design concepts, it provides a new way for the bionic form design of high-rise buildings as well as opens up a new dimension for the study of human survival experience and aesthetic tastes. Designers who are responsible for the future world must deeply interpret the relationship among man, nature and the whole life world and establish emotional and spiritual communication with all living things. Buildings, as natural artificial things, should be everlastingly new as nature and follow nature to survive. Only in this way can our world be thriving.

\section{SUMMARY AND PROSPECT}

When we are able to establish the current practice guidelines from the future vision, we can effectively avoid the immediate-interest-focused modern lifestyle. Man must stop randomly trampling on nature, change the survival attitude of conquering and possessing, guide behavior with rational emotions, restore the primitive surviving state of life and guard the harmonious relationship between humans and nature. The world which is full of harmonious ecological civilization is really the beautiful home for humans' poetic dwelling. Bionic design is the joint point of human social production activities and nature. With the ability to reason and create superior to other creatures, humans learn from nature to constantly enrich their material while getting closer to nature.

Form bionic design of high-rise buildings is constantly creating more pleasant and satisfactory lifestyle for humans, achieving truly harmonious coexistence between human society and nature. Professor Xianjue Liu predicts, "The future city will be bionic and ecological [4]." Future ecological civilization should be built on the basis of humans' deep understandings of the natural ecological laws. "In the coming era, biology and living animals will be respected more, and as a corollary, humans' concept of nature will return to its rich and specific diversity, self-determined freedom, intrinsic meaning, value and the depth and complexity and even mystique of its 
characteristics. In short, it will be an organism age [5]." This statement reflects the "pro-life nature" called by ecological and cultural forerunners. "Pro-life nature" makes humans embrace all living things and open to nature with their souls.

Bionic form design of high-rise buildings blossoms with radiant splendor. It applies the principles of bionics to achieve ecological high-rise buildings. Future design of high-rise buildings should proceed in everything from the human environment and highlight the natural property of the artificial environment. Bionic design will become the new design practice ideas for high-rise buildings. Innovation based on ecological problems solved with reference to bionics will lead the style of future high-rise buildings.

\section{NoTE}

[1] Yu Jing: Study on Form and Color of Bionic Design, Master Degree Thesis of Hunan University (2008), p1-2.

[2] "Design Bionics" on http://baike.baidu.com/view/767310.htm

[5] Donald Worster: Nature's Economy, translated by Hou Wenhui, p370, the Economic Press, Beijing, 1999

\section{REFERENCES}

[1] Xianjue Liu: The New Trend of Bionic Architectural Culture, World Architecture, April 1996.

[2] Xianjue Liu: The New Trend of Bionic Architectural Culture, World Architecture, April 1996. 